Journal of Social Sciences 8 (3): 325-331, 2012

ISSN 1549-3652

(C) 2012 Science Publications

\title{
Comparative Analysis of Postmodern Design for Information Technology in Education in Relation to Modernism
}

\author{
Saeid Zarghami Hamrah and Parvin Bazghandi \\ Department of Philosophy of Education, Faculty of Psychology and Education, \\ Tarbiat Moallem University, No. 49, Mofateh Ave, Tehran, Iran
}

\begin{abstract}
Problem statement: The purpose of present study is a comparative analysis of the philosophical bases of postmodernism in relation to modernism and suggesting the necessities of each base in the designing information technology in education. Approach: The research method for the present study was comparative analysis. Results: The first base was rejection of objective view toward the universe and accepting the "pre-objective universe". In this regard, it was suggested that information technology should be considered in relation to and as a component of life. The second base was doing away with totality. The necessity of this base was in the rejection of universal approaches and designing for specific situations. The third base was uncertainty. Regarding this base, it was suggested that the educational software provide a text in which the learner confront subjects for questioning and interpreting. The forth base was focusing on the complexities of the phenomena. In this ground, it was especially necessary for the design to be integrational. Conclusion/Recommendations: It seems that postmodernism view has been able to provide the possibility of recreating information technology in education through going beyond the basic assumptions of modernism. At last and in order to escape the metanarrative view toward postmodern ideas, we cannot regard the recommended solutions by postmodernists as the definite, final and general solution for educational issues of present and past times. But, we can look at them for further illumination of technological education condition of the present time.
\end{abstract}

Key words: Information Technology (IT), comparative analysis, inquiry seems necessary, possible relations, basic assumptions, western culture

\section{INTRODUCTION}

Modernism is mostly considered as the period which "started from 19th century and continued up to the World War II" (Craig, 2005), but the philosophical roots of this movement can be found in the ideas of Beacon and Descartes which gives reality to philosophical renaissance. On the other side, especially from the second half of 20th century a range of ideas was emerged in different fields which challenged the basic assumptions of western culture in the recent centuries. For example, some movements were formed in the art which had rejection of realism as one of the important elements of modern art. Also, relativity physics changed its attention from reality, which was the focus of classic physics, to measurement (Craig, 2005). In the field of philosophy also a range of thoughts were emerged all of which, in spite of variability, challenged the basic assumptions of western philosophy.

In the present study, first some of the philosophical bases of modernism view are outlined. Then, the criticism of postmodernism on these bases and approaches of this movement and the implications of each in designing Information Technology (IT) in the field of education is outlined and recommended.

To state the significance of this study it is worth mentioning that due to the wide application of IT in the field of education and many related issues and events, intellectual or philosophical inquiry seems necessary. On the other side, it seems that the postmodernism thinking tradition is formed on the basis of modernism historical process and the lessons obtained from its failures and the solutions are also offered with the aim of confronting those problems. Therefore, designing the application of IT in the field of education according to the postmodern views, in fact, is a sign of attending to failures of modern western culture in employing IT in the field of education.

\section{MATERIALS AND METHODS}

The present study has a philosophical nature with regard to its purpose and since the research methods are

Corresponding Author: Saeid Zarghami Hamrah, Department of Philosophy of Education, Faculty of Psychology and Education,

Tarbiat Moallem University, No. 49, Mofateh Ave, Tehran, Iran 
very diverse in the domain of philosophy and philosophy of education (Given, 2008; Heyting et al., 2001), a method should be chosen which is able to meet the specific purpose of the study. Accordingly, in the present study, comparative analysis is used as one of the methods of qualitative content analysis (Given, 2008). As Rihoux (2006) believes comparative analysis is comparison between subjects, predicates, collections, individuals, groups or time periods which reveals the similarities and differences between them. The main part of comparative analysis is called "constant comparative analysis":"... It involves taking one entity or piece of data, such as a statement, an interview, or a theme and comparing it with others to identify similarities or differences. By isolating these aspects, it is then possible to develop a conceptual model of the possible relations between various entities "(Given, 2008). Therefore, in this study the basic concepts and predicates used in modern and postmodern philosophies, after distinguishing and describing, are compared through constant comparative analysis in order to enable the devise of postmodern information technology for education.

Bases of modernism: The modernism movement can be compared to a building which is on a philosophical foundation and is founded on some bases. Foundation of modernism is dualism of subject and object that is suggested by Descartes (Voss, 1993). Hanks (2009) indicates that in ancient Greek, the subject had been the basis of any identification but it was not dependent on human and "self". Descartes, who intended at offering metaphysical bases which are definite and also the basis for any definiteness, ascribes subject to human and self. In this way, human being is considered in a position that reality, whatever it is, would gain meaning in relation to him. Human being with such a view should regard universe and whatever in it as objects in front of him and he should know them and to overcome them. Heidegger calls this situation as subjectivism and human's new worldview as technological.

In the present study and based on such a ground, four bases of mechanical and objective view toward the universe, totality, certainty and simplification of the phenomena are considered. Modernism had so many promises such as dominance over nature, solving the experimental and social problems, democracy, justice and peace (Bromley and Apple, 1998). Some of the promises like dominance over nature and social welfare were highly attained, but as Hanks (2009) also pointed out the consequences like invasion and destruction of nature were resulted. But some other promises like democracy, justice and peace faced basic dead-end in the first half of the 20th century. So, Lyotard (1984) considers the furnace for burning humans by Hitler as the end of modernism.

Postmodern bases in designing information technology: Postmodernism creates new bases with regard to the crisis caused by the bases of modernism.

Rejection of objective view toward universe and accepting "pre-objective universe": Subjectivism is rejected in the postmodernism view. That is, in such a view human being cannot go beyond the universe as a subject and to understand the universe as a subject. As Murphy and Pardeck (1985) believe, this universe is a live and pre-objective universe which appears in the learner's experience and he is also a part of it. Therefore, the point is understanding life which is possible not through learner's facing with universe but through using language and since language has a metaphoric, historical and cultural nature, all of the phenomena adapt a metaphoric, historical and cultural nature.

Signification of information technology in relation to "life: In modernism view, information technology is regarded as an instrument which is used by the learner in order to fulfill the needs and remove limitations; with this view information technology is neutral and it can lead to cultural consequences through independent development. This is the reason modernism supporters warn about using information technology in the education in a proper way. For example, Solomon (1999) argues that the software's with educational value are those designed based on group and interactional learning methods.

But in the postmodern view, information technology is a form of human action and the result of his language and therefore it is metaphoric and gains "aesthetic" nature, which means that it is regarded as art work which can be criticized (Saha, 1997). According to the value and cultural characteristic of information technology, the responsibility of the experts is not merely limited to applying information technology in education, but they are responsible for cultural preassumptions for the formation of information technology as well.

Rejection of totality: The rejection of totality is one of the principles of postmodern idea. Lyotard (1984) defines postmodernism as "incredulity toward metanarratives" (p. XXIV). He divides different fields of knowledge to scientific and narrative knowledge and concludes that each of them has its own specific rules, hence union, unity and attaining totality is not possible. 


\section{J. Social Sci., 8 (3): 325-331, 2012}

One of the displays of rejection of totality is attention and respect to "other's culture". Derrida (2001) thinks that the solution to go beyond subjectivism is paying attention to "other" and by the expansion of Saussure's linguistic studies to the field of culture, believes that understanding "other" necessitates recognition of his "difference" and respecting him. "Other" could be supervisor on opposite sex, minority group, social class, or other race, so, postmodern teachers focus on subjects like anthropology, ecology and feminism studies.

For example, Thomas (2000) proposes that the teachers should be familiarized with the mentioned studies and these studies should be integrated into the school curriculum too.

Designing for specific condition: In postmodern view, the universal approaches are rejected and the focus shifts to specific condition. As Voithofer and Foley (2002) believes, the failure of information technology in modern education and the consequences which resulted, including unequal educational relationships, is due to the fact that information technology is applied to the educational environment without proper integration with the cultural condition of the learner. For the proper adaption, he recommends focusing on instructional goals as well as moral and social goals for different cultural conditions. In order to attain the instructional goals for different groups it is necessary to devise the educational softwares in a way that the knowledge is constructed and understood by each individual learner. Cheserbo (1999) argues that IT has provided an opportunity here. He believes that any learner builds his/her own specific communication system in the virtual environment. He believes that surfing the internet by the learners is not led by the same goal; hence the basis of such knowledge is unique for each learner. In this way Internet could lead to a condition in which the knowledge can be constructed and understood individually by each learner.

Regarding the moral and social goals of different groups the following suggestions could be offered.

Designing with respect to the ecology of learning system: That is the designer should consider some criteria which play significant role in the learning environment. Among these criteria we can mention race, social class and gender. Therefore, it is necessary for the design phase to be based on cultural studies, curriculum theories, the specific subject and the information and communication sciences. A cultural study encompasses a wide range of disciplines and viewpoints including sociology, history, linguistics, feminism, anthropology, psychoanalysis and philosophy (O'Sullivan, 1994). In the modern stance such a wide view was neglected. For example, Weinman and Haag (1999) consider the present educational softwares as a symbol of masculine culture and believe that feminism studies lack in the design of these softwares.

Designing based on "pluralism" and "multiculturalism: In designing information technology on the basis of pluralism, it is necessary to attend to designing educational softwares which provides an atmosphere of discussion for different learners by using various methods that result in reinforcement of human relationships among them as well as mutual understanding. In designing based on "multiculturalism" also there is no premier universal culture and none of cultures is not in the place to judge other cultures and to decide for them. In such a situation the possibility of recreating education is provided and in the same way information technology, due to its specific capacity of to create an atmosphere of discussion among learners from different cultures through simple ways like electronic mail and chat, would play a central role.

Uncertainty: The third base of modernism is uncertainty and regarding this point Brass (2000) calls the dominant cultures of modern era as "certainty culture". For example, the advocates of modernism support the softwares that have designed the process of learning on the basis of scientific and effective learning theories like cognitive theories. This view shows that advocates of modernism only accept specific types as the best design. On the other side, Lyotard (1984) thinks that there is similarity between language games of Wittgenstein and Nietzsche's emphasis on perspective in any type of judgment; accordingly he also considers science as language game (p. 33). On such a ground he criticizes the scientific theories that relying on their specific criteria and consider anything out of those criteria as inappropriate and insignificant. Indicating to the point that language is not the reflection of reality in displays such as literature, philosophy and science, but it has a metaphoric, ironic and allegoric and therefore interpretive nature, Derrida also emphasizes that each system of thoughts, includes meanings and various voice (Hamrah, 2011).

Information technology creates an atmosphere of questioning: Regarding the postmodern uncertainty, it is necessary for information technology not to be the medium for transferring information and principles, but it should create an atmosphere of questioning. In 


\section{J. Social Sci., 8 (3): 325-331, 2012}

this way software provides a text in which the learner faces subjects to be interpreted and understood and through using imagination power and also interpreting symbols in the texts he would discover secrets about the text and by generalizing he would appreciate the role of interpretation and understanding in social life and facing the reality.

Complexity and dynamism: On the basis of the law by Descartes which states that for investigating each phenomenon it should be divided into its components (Voss, 1993), the fourth base of modernism is simplification of phenomena for systematic and precise perception of them. The learning system of a program which divides the subject of learning into its components and requires the learners to pass through a linear and interrelated process from easier levels to more difficult ones, is a distinctive example of modernism view in designing information technology.

But, the postmodern world is a complicated and multi-dimensional world. The emphasis by prominent representative of postmodern like Lyotard, Derrida, Foucault, Rotry and Deluze on ideas of difference, inequality, dissimilarity, incoherence, multidimensionality and interweaving (Usher and Edwards, 1994) also conveys the same belief. These characteristics for applying information technology require some necessities:

Multi-dimensional planning and investigating of the subject matter: In order to attain this aim it is necessary for the teacher to avoid one-dimensional review of the subject matter by using the educational software, just like the designers and to pay attention to unconscious issues and specific cultural and social condition.

Integrational design of knowledge: Integration is a theory in the field of curriculum studies and encompasses a wide range of views and theories. In simple words, the supporters of integration believe that natural and social phenomena are unique and connected. But the simplifying view of modern divides the knowledge about these phenomena into human sciences and natural sciences and divides each of categories into disciplines like arts, philosophy, physics and chemistry. Points out that these categories have overlooked the natural order that govern the phenomena.

On this basis postmodern researchers support multidisciplinary and interdisciplinary approaches in the design phase. In this way, the software is not designed according to artificial disciplinary categorizations and therefore one of the solutions for developing multidisciplinary and interdisciplinary studies is designing software based on the concepts that can be the subject of interdisciplinary studies. On the other words, prior to differentiating categories of knowledge or disciplines, human being had faced issues and phenomena of the universe and had thought about them. Matter, energy, life, time, air pollution, justice and ethics are among the concepts and subjects that, on the one side, might concern each human being and, on the other side, are not restricted to any specific discipline or knowledge. As an example, the concept of matter is considered in physics, chemistry and biology; it is also regarded in philosophy when investigating the fields of metaphysics, materialism and spiritual philosophies. As far as the energy is concerned, we can refer to the energies produced by sun, oil, food and the smile of a teacher which could not be comprehensively studies through physics. Pollution is also an issue that could be considered from different aspects of biological, cultural, economical and social. Jordan (1989) also refers to many issues and concepts, including time, equilibrium, holism and reductionism organism and other as interdisciplinary fields. Holton claims that the number of these interdisciplinary fields exceeds one hundred.

Schank and Arbor (2002), share their experience of designing educational software. They introduce the software called Slay the Dragoon which was designed according to Story-Centered Curriculum (SCC). SCC is a story-like and integrative curriculum in which all of the faculties' students and different departments take part and gather information in order to fulfill their part. In this way, they actively participate in their own learning. In SCC constructing an integrative story includes 5 stages: (1) setting the goal and responsibilities for each student, (2) determining the key activities for attaining the goals, (3) predicting the significant events that may stop students from attaining the goal, (4) designing a story that takes all the mentioned steps into account and (5) designing the story software. Besides integrating the subjects, SCC defines a role for students for over one year. By doing this, it offers interconnected subjects for different years of education. Schenk and Arbor introduce the Slay the Dragon as: once upon a time some dragons attacked a city. The frightened citizens decided to develop a new curriculum in order to grow warriors to fight against the dragons. Students of various faculties including medicine, law, engineering and human sciences decided to take action. The best scientific department would be the one which teaches how to kill the dragons... (p. 1). 


\section{RESULTS AND DISCUSSION}

Postmodernism is generally considered as the criticism of rational foundations of modernism. In the study, In order to present theoretical bases of modernism, the principle of dualism of subject and object is investigated. If it is accepted that the universe is not the encounter of subject and object, then IT also is involved in and is a part of "life".

Therefore, it could not be claimed that IT is an objective and neutral means which merely needs to be applied appropriately, but the origination and development of IT is a social and cultural phenomenon. The same as other phenomena, it could be the result of various concealed intentions and goals. Taking this view, we are able to recognize the authoritarian and cruel intentions and goals of those in political and economical powers of entering and employing IT in the field of education and to discover the ideological and unmentioned aspects of curriculum based on IT such as gender and social inequalities. By going beyond the dichotomy of subject and object, learning is no more acquiring unchanging and certain principles but it would be an interpretive, dynamic and interdisciplinary process. In this way knowledge is challenged and its symbolic interpretive nature would be further uncovered and learners also grasp the importance and the role of interpretation in the formation of society and life. Therefore, the post-modern view managed to take a step forward and raise the possibility of recreating IT in the field of education by going beyond ontological and epistemological presuppositions of Descartes. The findings of this study could be summarized in the following Fig. 1.

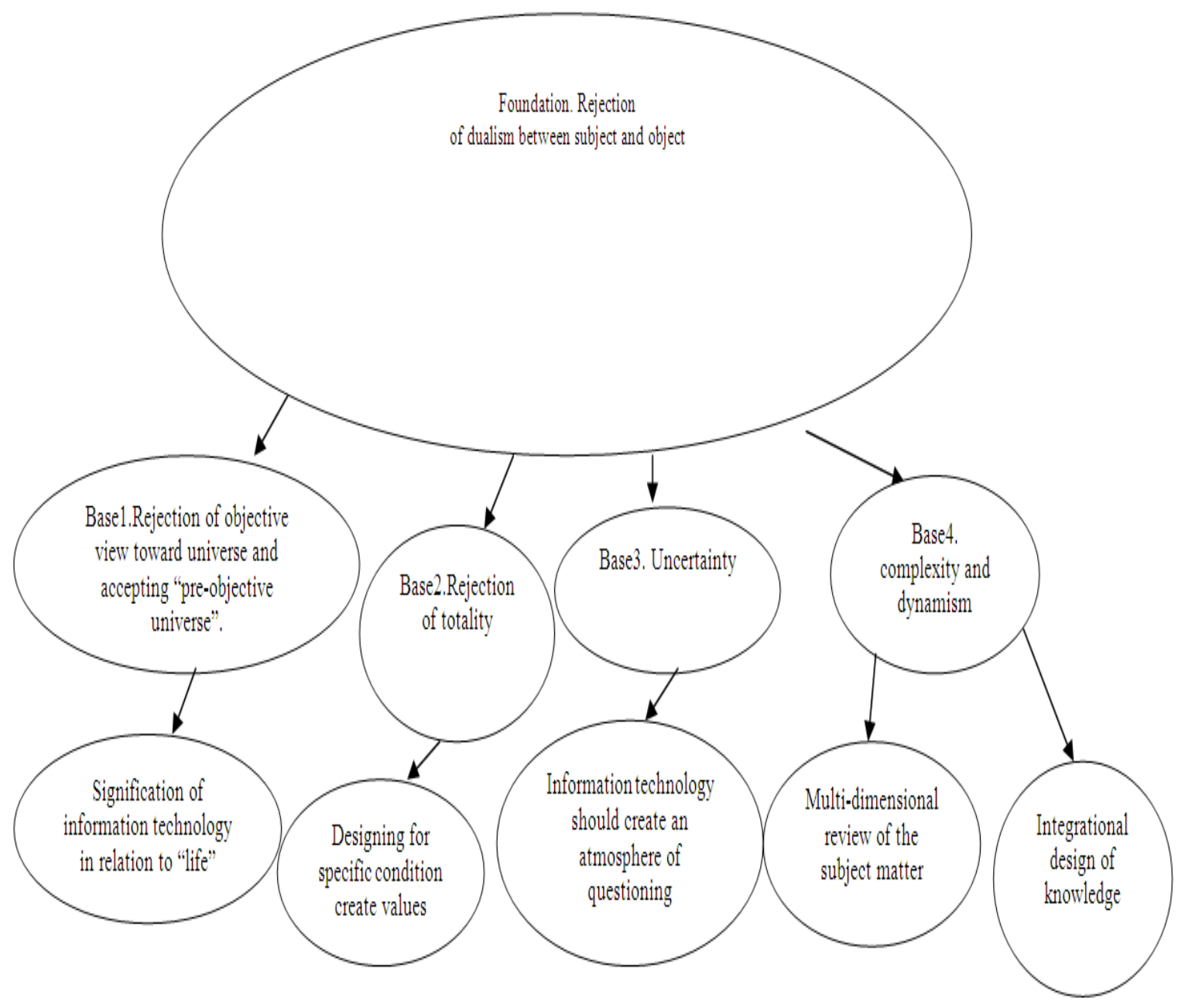

Fig. 1: Theoretical framework of postmodern design for information technology such as educational technology 


\section{J. Social Sci., 8 (3): 325-331, 2012}

\section{CONCLUSION}

But the post-modern ideas could also be criticized. It seems that if educational goals are categorized as educational goals and socio-cultural goals, the postmodern ideas underscore socio-cultural goals and overlook educational goals and contents as well as scientific achievements of modern era in this field by an overemphasis on crossing the traditional borders. On account of IT, nowadays the significant educational ideas such as learning by doing, learning by games and learning beyond the school setting are attained further than past. In this condition, on the one side, the wide and immediate availability of information has reduced the need for learners to memorize knowledge and information and, on the other, the time spent for gathering information is saved and the process of science production is accelerated which has led to improvement of life quality. These educational achievements of modern ideas which resulted from centuries of thinking and attempting by human being are overlooked by post-modern thinkers. As a result of this, IT does not get the chances it used to have in modern ideology in the field of education.

Another problem is concerned with "metanarrative" viewpoint in designing IT. Post-modern thinkers claim that there is no meta-discourse and different discourses such as science, philosophy and arts are different narratives and these narratives are not able to judge other narratives. Rorty (cited in Saha, 1997) and Lyotard (1984) regard philosophy from the same point of view. To these scholars philosophy is finding the eternal and beyond-the-time truth and it is not ethical principle and judgment criterion for deciding about other narratives. Philosophy is a game of language the same as other cultural representations; it is a narrative alongside other narratives and not superior to them, hence it could not be a framework for judging about them. Consequently, philosophy is not theorization and judging about other narratives, but it aims at criticizing (not with general criteria), revising events form other point of views and illuminating about the present condition. It seems that by adherence to these post-modern ideas, post-modernism could not be in a "transcending" place to judge the modernism ideas. In the same line, it could not also claimed that it is able to offer a unique, absolute and final solution by theorizing for all educational issues and problems, hence the post-modern solutions could not be assumed as general and absolute guidelines for existing and previous challenges. Categorizing and investigating ideas do not imply rejecting one theory and supporting the other, but they offer criticism and illumination on some aspects of present technological education condition.

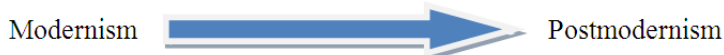

Fig. 2: Linear and evolutionary pattern in designing IT

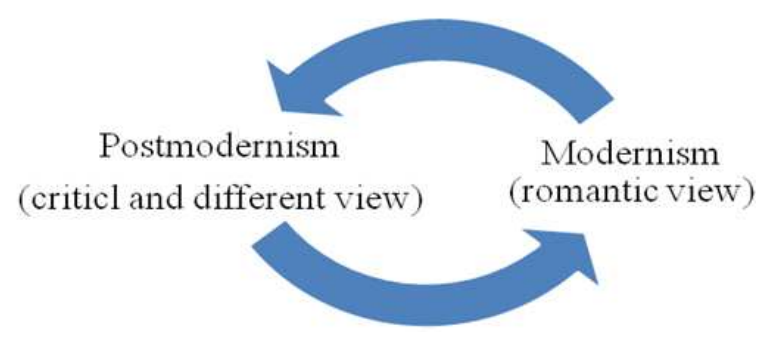

Fig. 3: Cyclic and compound pattern in designing IT

According to the presented discussion, a cyclic and compound pattern is recommended instead of a linear and evolutionary one in designing IT. If ideas are considered on a directional, linear and evolutionary line (Fig. 2), then the post-modern views, as a comprehensive view, should be taken as the basis for theoretical design of IT in educational setting. But if the views are considered in a compound and cyclic pattern (Fig. 3), different understanding and idea are emerged.

Experts suggest that after the fulfillment of the IT "dream" in the field of education, we should focus on "criticizing" the failures and defective consequences and propose a different design through novel ideas. But this different design necessitates a novel "dream" which results from criticism, interpretation, evolution and renewal. Adapting this view, the compulsory necessities of applying IT in the field of education by any school of thought and the general and absolute solutions they offered for present and previous educational concerns are not acceptable. In other words, the aim of categorization and investigation of ideas is to questions the how of IT in education and seeking further clarification of the situation. Each idea clarifies a part of reality about IT and by taking a critical view one could evaluate their strengths and weaknesses and also contrast their explanation of IT. In this manner the condition of technological education could be foreseen and improved in other stages of re-evaluation.

\section{REFERENCES}

Brass, T., 2000. Peasants, Populism and Postmodernism: The Return of the Agrarian Myth. 1st Edn., Routledge, London, ISBN: 0714649406, pp: 380 . 
Bromley, H. and M.W. Apple, 1998. Education, Technology, Power: Educational Computing as a Social Practice. 1st Edn., SUNY Press, New York, ISBN: 0791437973, pp: 263.

Cheserbo, J., 1999. Communication technologies as symbolic form: Cognitive transformations generated by the internet. Int. J. Commun., 47: 40-49.

Craig, E., 2005. The Shorter Routledge Encyclopedia of Philosophy. 1st Edn., Routledge, London, New York, ISBN: 0415324955, pp: 1077.

Derrida, J., 2001. Writing and Difference. 2nd Edn., Routledge, London, New York, ISBN: 0415253837, pp: 446.

Given, L.M., 2008. The Sage Encyclopedia of Qualitative Research Methods. 1st Edn., SAGE Publications, London, ISBN: 1412941636, pp: 1014.

Hamrah, S.Z., 2011. Deconstruction of knowledge nature in the views of derrida and feyerabend: The possibility and necessity of interdisciplinary studies in higher education. Int. J. Interdisciplinary Soc. Sci., 5: 481-490.

Hanks, C., 2009. Technology and Values: Essential Readings. 1st Edn., John Wiley and Sons, Chichester, U.K., ISBN: 1405149000, pp: 542.

Heyting, F., D. Lenzen and J.P. White, 2001. Methods in Philosophy of Education. 1st Edn., Routledge, London, New York, ISBN: 0415242606, pp: 185.

Jordan, T., 1989. Themes and schemes: A philosophical approach to interdisciplinary science teaching. Synthese, 80: 63-79.

Lyotard, J.F., 1984. The Postmodern Condition. 1st Edn., University of Minnesota Press, Minneapolis, ISBN: 0816611734, pp: 110.

Murphy, J.W. and J.T. Pardeck, 1985. The technological world-view and the responsible use of computers in the classroom. J. Educ., 167: 98-117.
O’Sullivan, T., 1994. Key Concepts in Communication and Cultural Studies. 2nd Edn., Routledge: London, New York, ISBN: 0415061733, pp: 637.

Rihoux, B., 2006. Qualitative Comparative Analysis (QCA) and related systematic comparative methods: Recent advances and remaining challenges for social science research. Int. Soc., 21: 670-706. DOI: 10.1177/0268580906067836

Saha, L.J., 1997. International Encyclopedia of the Sociology of Education. 1st Edn., Pergamon Press, Oxford, ISBN: 0080429904, pp: 961.

Schank, R.C. and A. Arbor, 2002. Every curriculum tells a story. Int. J. Technol. Direct., 27: 14-34.

Solomon, G., 1999. Collaborative learning with technology. Int. J. Technol. Learn., 1: 51-65.

Thomas, E., 2000. Culture and Schooling: Building Bridges between Research, Praxis and Professionalism. 1st Edn., J. Wiley and Sons, Chichester, ISBN: 0471897884, pp: 312.

Usher, R. and R. Edwards, 1994. Postmodernism and Education. 1st Edn., Routledge, London, New York, ISBN: 0415102812, pp: 246.

Voithofer, R. and A. Foley, 2002. Post-IT: Putting postmodern perspectives to use in instructional technology--a response to solomon's "toward a post-modern agenda in instructional technology. Educ. Theory Res. Dev., 50: 5-14.

Voss, S., 1993. Essays on the Philosophy and Science of Rene Descartes. 1st Edn., Oxford University Press, New York, Oxford, ISBN: 0195075501, pp: 342 .

Weinman, J. and P. Haag, 1999. Gender equity in cyberspace. Educ. Leader., 56: 44-49. 